\title{
GLUCOCORTICOID RESPONSE TO INTRAMUSCULAR ACTH STIMULATION IN CRITICALLY ILL PATIENTS
}

Samarendra Nath Das ${ }^{1}$, Nirmal Chandra Sahu², Dipti Ranjan Darjee 3 , Sanat Kumar Mishra4, Sai Swaroop ${ }^{5}$, Sarada Priyadarshini Suna 6 , SK. Maheboob Salim7, Pravat Kumar Thatoi ${ }^{8}$

${ }^{1}$ Associate Professor, Department of Medicine, SCB Medical College, Cuttack.

${ }^{2}$ Assistant Professor, Department of Medicine, SCB Medical College, Cuttack.

${ }^{3}$ Senior Resident, Department of Medicine, SCB Medical College, Cuttack.

${ }^{4}$ Senior Resident, Department of Medicine, SCB Medical College, Cuttack.

${ }^{5}$ Postgraduate Student, Department of Medicine, SCB Medical College, Cuttack.

${ }^{6}$ Postgraduate Student, Department of Medicine, SCB Medical College, Cuttack.

${ }^{7}$ Assistant Surgeon, SCB Medical College, Cuttack.

${ }^{8}$ Assistant Professor, Department of Medicine, SCB Medical College, Cuttack.

ABSTRACT

\section{BACKGROUND}

Cortisol (Glucocorticoid) is the main hormone in host response to stress. Its secretion from adrenal glands depends on integrity of hypothalamic-pituitary-adrenal (HPA) axis. Adrenocorticotropic hormone (ACTH) is the stimulant for cortisol secretion from adrenal glands. Adrenal insufficiency (AI) is often present in critically ill patients and is diagnosed by ACTH stimulation test using intravenous (IV) injection of Synacthen (Tetracosactide) which is not freely available in our part. Another synthetic corticotrophin (Acton Prolongatum) prepared by Ferring pharmaceuticals can be used for intramuscular (IM) ACTH stimulation test for assessment of adrenal function.

Aims \& Objectives- To measure the basal serum cortisol level at 8.00-9.00 a.m. then at 60 min. \& 3 hours after IM ACTH stimulation and to find out glucocorticoid response in critically ill patients.

\section{MATERIALS AND METHODS}

A descriptive study was designed in the Medical ICU of SCB Medical College, Cuttack, 46 critically ill adult patients with various diseases admitted to Medical ICU and were having or suspected of having some degree of adrenocortical dysfunction on the basis of prolonged hypotension for more than 6 hours despite adequate fluid challenge and/or need for vasopressors/inotropes, were included in this study for the period from Sep. 2013 to Sep. 2015.

\section{RESULTS}

Out of total 46 ill patients, 25 patients were diagnosed as adrenal insufficiency. Amongst them, 14 were male and 11 were female. Most of them presented with various combinations of hypotension, fever, nausea, vomiting, fatigue, pigmentation, weakness and irritability.

\section{CONCLUSION}

We concluded that intramuscular Acton Prolongatum can be used for ACTH stimulation test in critically ill patients to diagnose adrenal insufficiency (AI).

\section{KEYWORDS}

Critically Ill Patient, Intensive Care Unit (ICU), Adrenal Insufficiency, Acton Prolongatum, ACTH Stimulation Test.

HOW TO CITE THIS ARTICLE: Das SN, Sahu NC, Darjee DR, et al. Glucocorticoid response to intramuscular ACTH stimulation in critically ill patients. J. Evolution Med. Dent. Sci. 2017;6(74):5292-5295, DOI: 10.14260/Jemds/2017/1149

\section{BACKGROUND}

Severe illness and stress activate the hypothalamic-pituitaryadrenal (HPA) axis and stimulate the release of corticotrophin (adrenocorticotropic hormone or ACTH) from the pituitary gland, which in turn increases the release of cortisol from adrenal cortex. ${ }^{1,2}$

Financial or Other, Competing Interest: None.

Submission 07-08-2017, Peer Review 01-09-2017,

Acceptance 06-09-2017, Published 14-09-2017.

Corresponding Author:

Pravat Kumar Thatoi,

Flat-104, Aryabhatta Complex,

College Square,

Cuttack-753003,

Odisha, India.

E-mail: drpravatthatoi@yahoo.co.in

DOI: $10.14260 /$ jemds $/ 2017 / 1149$
This activation is an essential component of the general adaptation to illness and stress and contributes to the maintenance of cellular and organ homoeostasis. Adrenalectomised animals succumb rapidly to haemorrhagic and septic shock and steroid replacement is protective against these challenges. ${ }^{3,4}$ Even minor degrees of adrenal insufficiency increases the mortality in critically ill or injured patients. ${ }^{5}$ Our study aims to diagnose adrenal insufficiency in critically ill patients on the basis of ACTH stimulation test.

\section{MATERIALS AND METHODS}

After clearance from institutional ethics committee (IEC), we have designed a descriptive study in the Medical ICU of SCB Medical College, Cuttack, 46 critically ill adult patients with various diseases admitted to Medical ICU were included in the study from Sept. 2013 to Sept. 2015. The samples were taken conveniently. Informed consent was obtained from the patient's next of kin. 
Patient selection criteria: Critically ill patients of various diseases admitted to Medical ICU and were having or suspected of having some degree of adrenocortical dysfunction on the basis of prolonged hypotension for more than 6 hrs. despite adequate fluid challenge and/or need for vasopressors/inotropes, were included in the study.

Exclusion criteria: Patients were excluded if they had known previous conditions that may have disrupted the HPA axis. $6,7,8,9$

In selected patients, detailed history and thorough clinical examination was done and disease activity score was recorded in a proforma. Basal cortisol was estimated between 8.00 a.m. to 9.00 a.m. ( $0 \mathrm{hr}$.), then they underwent ACTH stimulation test by intramuscular (IM) injection of 25 units of Acton Prolongatum (synthetic corticotropin carboxymethyl cellulose-available as $5 \mathrm{~mL}$ vial with concentration of 60 units $/ \mathrm{mL}$ ) and blood collected at $1 \mathrm{hr}$. for estimation of serum cortisol. Another blood sample at $3 \mathrm{hrs}$. was also collected in 20 patients for further analysis and correlation. We determined the absolute and proportional changes between the basal cortisol level and the peak response to ACTH (Delta cortisol at $1 \mathrm{hr}=$ difference of values of serum cortisol between $1 \mathrm{hr}$. and $0 \mathrm{hr}$.). Cortisol was measured by Electrochemiluminescence immunoassay (ECLIA) used on Roche Cobas e 411 immunoassay analyser. The following investigations were done daily, complete blood count (CBC), plasma electrolytes, glucose levels, serum creatinine and liver function tests, arterial lactate and blood gases.

Hydrocortisone administration (starting at $100 \mathrm{mg}$ intravenous, every 8 hours) was initiated while awaiting the ACTH test results. If the test was considered normal, hydrocortisone was discontinued.

\section{Statistical Analysis}

The observed data set was statistically analysed by using IBMcompatible Statistical Package for the Social Sciences (SPSS) version 20.0. The qualitative data were expressed as numbers (\%), while the continuous quantitative data as mean \pm standard deviation (SD) and the data was statistically analysed by using the following tests: Student t-test, Chi-square test. A p-value of $<0.05$ was considered significant and $p$-value of $<0.001$ was considered highly significant, while p-value of $>0.05$ was considered not significant.

\section{RESULTS}

\begin{tabular}{|c|c|c|c|}
\hline Sl. No. & Sex & No. of Cases & Percentage (\%) \\
\hline 1 & Male & 32 & $69.56 \%$ \\
\hline 2 & Female & 14 & $30.43 \%$ \\
\hline $\mathbf{3}$ & M + F (Total) & $\mathbf{4 6}$ & $\mathbf{1 0 0 \%}$ \\
\hline \multicolumn{3}{|c|}{ Table 1. Sex Distribution of Suspected Cases of AI } \\
\hline
\end{tabular}

Out of 46 study population, 32 were male and 14 were female [Table 1].

\begin{tabular}{|c|c|c|c|}
\hline Sl. No. & Sex & No. of Cases & Percentage (\%) \\
\hline 1 & Male & 14 & $56 \%$ \\
\hline 2 & Female & 11 & $44 \%$ \\
\hline $\mathbf{3}$ & Total & $\mathbf{2 5}$ & $\mathbf{1 0 0 \%}$ \\
\hline \multicolumn{3}{|c|}{ Table 2. Sex Distribution of Relative Adrenal } \\
Insufficiency (RAI) Patients from Total Patients, $\boldsymbol{n}=\mathbf{2 5}$ \\
\hline
\end{tabular}

Out of 46 patients, 25 (54.39\%) patients have relative

Out of 20 cases, 5 patients had $\leq 500 \mathrm{nmol} / \mathrm{L}$ basal serum cortisol, and 13 patients had Delta cortisol at $1 \mathrm{hr}$. of $\leq 250 \mathrm{nmol} / \mathrm{L}$ and adrenal insufficiency (RAI) and $21(45.65 \%)$ patients show the normal response to ACTH stimulation test. Amongst the 25 RAI patients, 14 (56\%) were male and 11 (44\%) were female. [Table 2].

\begin{tabular}{|c|c|c|c|}
\hline Sl. No. & Age (In years) & No. of Cases, $\mathbf{n = 2 5}$ & (\%) \\
\hline 1 & $15-30$ & 3 & $12 \%$ \\
\hline 2 & $31-45$ & 12 & $48 \%$ \\
\hline 3 & $46-60$ & 7 & $28 \%$ \\
\hline 4 & $>60$ & 3 & $12 \%$ \\
\hline \multicolumn{3}{|c|}{ Table 3. Age Distribution among RAI Patients. $n=25$} \\
\hline
\end{tabular}

Out of the total RAI cases, 12 (48\%) cases were found in the age group of 31-45 years, 7 (28\%) were between 46 to 60 years, $3(12 \%)$ from $15-30$ and rest 3 patients $(12 \%)$ were above 60 years. [Table 3].

\begin{tabular}{|c|c|c|}
\hline Symptoms & Patients No. & Percentage (\%) \\
\hline Weakness and Fatigue & 22 & $88 \%$ \\
\hline Nausea and Vomiting & 18 & $72 \%$ \\
\hline Fever & 17 & $68 \%$ \\
\hline Pigmentation & 6 & $19.98 \%$ \\
\hline Diarrhoea & 3 & $9.99 \%$ \\
\hline Hypotension & 25 & $100 \%$ \\
\hline Irritability & 9 & $29.97 \%$ \\
\hline Depression & 4 & $13.32 \%$ \\
\hline \multicolumn{3}{|c|}{ Table 4. Clinical Presentation of Cases of Adrenal } \\
\hline
\end{tabular}

All of the cases taken were hypotensive (100\%). 22 patients $(88 \%)$ of them presented with generalised weakness, 18 patients $(72 \%)$ presented with nausea and vomiting, 17 $(68 \%)$ with fever, $9(29.7 \%)$ patients were irritable and 4 patients $(13.32 \%)$ were depressive at the time of presentation.

Out of total 46 critically ill patients, 17 (36.95\%) patients had $\leq 500 \mathrm{nmol} / \mathrm{L}$ basal S. cortisol (at $0 \mathrm{hr}$.) and after ACTH stimulation test, $25(54.34 \%)$ patients had relative adrenal deficiency at $1 \mathrm{hr}$. S. cortisol level. [Table 5].

\begin{tabular}{|c|c|c|c|c|}
\hline $\begin{array}{r}\text { Sl. } \\
\text { No. }\end{array}$ & Sex & $\begin{array}{c}\text { S. Cortisol (Basal) } \\
\leq 500 \mathrm{nmol} / \mathrm{L} \\
\end{array}$ & \begin{tabular}{|c|} 
Delta $1 \mathrm{hr}$. \\
$\leq 250 \mathrm{nmol} / \mathrm{L}$
\end{tabular} & $\begin{array}{l}\text { Delta } 3 \mathrm{hrs} \text {. } \\
\leq 250 \mathrm{nmol} / \mathrm{L}\end{array}$ \\
\hline 1 & Male & 1 & \begin{tabular}{|c|}
6 \\
\end{tabular} & 4 \\
\hline 2 & Female & 4 & 7 & 4 \\
\hline 3 & Total & $5(25 \%)$ & $13(65 \%)$ & $8(40 \%)$ \\
\hline 4 & $\begin{array}{l}\text { Mean } \pm \\
\text { SD }\end{array}$ & $200.73 \pm 138.67$ & $150.67 \pm 64.42$ & $\begin{array}{l}174.03 \pm \\
74.86\end{array}$ \\
\hline \multicolumn{5}{|c|}{$\begin{array}{l}\text { Table 6. Result of ACTH Stimulation Test of } 20 \\
\text { atients and Level of S. Cortisol at } 0 \text { hr., } 1 \text { hr., } 3 \text { hrs. }\end{array}$} \\
\hline
\end{tabular}

\begin{tabular}{|c|c|c|c|}
\hline $\begin{array}{c}\text { Sl. } \\
\text { No. }\end{array}$ & Sex & $\begin{array}{c}\text { Basal S. Cortisol } \\
\mathbf{5} \mathbf{5 0 0} \mathbf{~ n m o l} / \mathbf{L}\end{array}$ & $\begin{array}{c}\text { Increment Of S. Cortisol } \\
\mathbf{5} \mathbf{2 5 0} \mathbf{~ n m o l} / \mathbf{L} \text { (Delta } \\
\text { Cortisol at 1 hr.) }\end{array}$ \\
\hline 1 & Male & 9 & 14 \\
\hline 2 & Female & 8 & 11 \\
\hline $\mathbf{3}$ & Total & $\mathbf{1 7}(\mathbf{3 6 . 9 5 \% )}$ & $\mathbf{2 5}(\mathbf{5 4 . 3 4 \% )}$ \\
\hline 4 & Mean \pm SD & $202.62 \pm 125.60$ & $137.51 \pm 68.18$ \\
\hline \multicolumn{4}{|c|}{ Table 5. Result of ACTH Stimulation } \\
Test from 46 Critically ill Patients
\end{tabular}


$8(40 \%)$ patients had Delta cortisol at $3 \mathrm{hrs}$. of $\leq 250 \mathrm{nmol} / \mathrm{L}$. [Table 6].

\begin{tabular}{|c|c|c|c|c|}
\hline Sl. No. & & Adrenal Insufficiency & Normal Adrenal Function & P value \\
\hline 1 & Cases & 25 & 21 & \\
\hline 2 & Age (Years) & $46.76 \pm 14.03$ & $51.08 \pm 12.49$ & $18: 3$ \\
\hline 3 & Sex (Male: Female) & $14: 11$ & $529.52 \pm 261.63$ & $<0.0001$ \\
\hline 4 & Basal Cortisol (nmol/L) & $137.51 \pm 68.18$ & $919.85 \pm 288.53$ & $<0.0001$ \\
\hline 5 & Post ACTH Cortisol (nmol/L) & $605.92 \pm 389.67$ & $332-1576$ & $<0.0001$ \\
\hline 6 & Range & $30.48-1650$ & $349.28 \pm 154.42$ & \\
\hline 7 & Delta Cortisol at 1 hr. (nmol/L) & $135.51 \pm 68.25$ & $264-775$ & \\
\hline 8 & Range & $0.83-250$ & & \\
\hline \multicolumn{4}{|r|}{ Table 7. Cortisol Levels in Study Group, $\boldsymbol{n}=\mathbf{4 6}$} \\
\end{tabular}

There was statistically significant difference in Basal cortisol, Post ACTH cortisol and Delta Cortisol between patients having $\mathrm{AI}$ and normal adrenal function.

\section{DISCUSSION}

The integrity of HPA axis is a major determinant of the host's response to stress. ${ }^{6,7}$ During stress, the activation of HPA axis is highlighted by increased corticotrophin release from the pituitary gland, ${ }^{10}$ enhanced adrenal secretory activity, 11,12 and high plasma cortisol levels However, whether endogenous glucocorticoid levels are adequate or constitute an independent predictor of death remains controversial.1,13,14 There are some studies which reported lower cortisol levels in non-survivors compared with survivors.15,16,17 For this reason, in stress, the evaluation of appropriateness of the activation of the HPA axis requires dynamic testing. Adrenal insufficiency is diagnosed when on stimulation test the peak serum cortisol is $<500 \mathrm{nmol} / \mathrm{L}(18 \mu \mathrm{g} / \mathrm{dL}),{ }^{18}$ alternatively it has been proposed that increment during ACTH stimulation test $<250 \mathrm{nmol} / \mathrm{L}(9 \mu \mathrm{g} / \mathrm{dL})$ or basal cortisol $<83 \mathrm{nmol} / \mathrm{L}(3$ $\mu \mathrm{g} / \mathrm{dL}$ ) can be considered as diagnostic of AI.18,19

Diagnostic evaluation of suspected cases of adrenal insufficiency is hindered by non-availability of injection Synacthen. To overcome this limitation, we used Acton Prolongatum (Corticotrophin Carboxymethyl cellulose) as intramuscular ACTH stimulation test. During standard Synacthen stimulation test (SST), serum cortisol is taken at 30 min. and $60 \mathrm{~min}$. intervals, because the serum cortisol (reflecting serum ACTH level) following injection of Synacthen peaks around this time. But the use of long acting corticotrophin carboxymethyl cellulose (Acton Prolongatum), plasma level of plasma 11- hydroxycorticosteroid reflecting the level of serum cortisol peaks around 1 to $3 \mathrm{hrs}$. (at $1 \mathrm{hr}$. $25.7 \mu \mathrm{g} / 100 \mathrm{~mL}$ and at $3 \mathrm{hrs} .37 .4 \mu \mathrm{g} / 100 \mathrm{~mL}){ }^{20}$ So we decided to take samples of serum cortisol at $0 \mathrm{hr}$., $1 \mathrm{hr}$. and 3 hrs. All the patients of control groups achieved normal stimulation of cortisol after intramuscular ACTH.

Intramuscular ACTH test with Acton Prolongatum is economically cheaper as compared to Synacthen. Synacthen costs around Rs. 3200 in the grey market. Each vial of Acton Prolongatum costs Rs. 1645 and contains 300 units ( 5 mL vial, 60 units $/ \mathrm{mL}$ ), thus 12 tests can be performed at a cost of Rs 130 each.

The incidence of adrenal insufficiency in critically ill patients presenting with shock varies and depends on the underlying disease and severity of illness. The reported incidence varies widely depending on the population of the patients studied and diagnostic criteria used to diagnose adrenal insufficiency.

Adrenal insufficiency: Subjects with post ACTH cortisol
$<500 \mathrm{nmol} / \mathrm{L}(18 \mu \mathrm{g} / \mathrm{dL})$ and Incremental response is decreased if serum cortisol rise was $<250 \mathrm{nmol} / \mathrm{L}(9 \mu \mathrm{g} / \mathrm{dL})$ from basal cortisol level post ACTH. ${ }^{21}$

Abhay Gundgurthi et $\mathrm{al}^{22}$ has done a study-"Intramuscular ACTH Stimulation Test for Assessment of Adrenal Function" and reported sex distribution among AI patients $\mathrm{M}: \mathrm{F}=28: 9$ and age distribution mean $\pm S D=33.0 \pm 18.8$ yrs. Present study shows the sex distribution among AI patients M: F =14:11 and mostly affected age group 31-45 years (48\%) with mean \pm SD is $46.76 \pm 14.03$ years. [Table-1] and [Table-3].

Hypotension refractory to fluids and requiring vasopressors is the most common feature of acute adrenal insufficiency. ${ }^{23}$ In the present study, $100 \%$ patients (25 patients) have hypotension and $88 \%$ (22 patients) had weakness and fatigue and $72 \%$ (18 patients) had symptoms of nausea and vomiting. Out of 25 patients, 17 patients (68\%) presented with fever. CNS dysfunction as irritability and depression is common, frequently as a result of underlying disease. In the present study, 29.97\% (9 patients) presented with irritability and $13.33 \%$ (4 patients) presented with depression as clinical features. [Table-4].

Acute adrenal insufficiency occurs in patients who are unable to increase their production of cortisol during acute stress. This includes patients with hypothalamic and pituitary disorders (Secondary AI) and patients with destructive diseases of adrenal glands (primary AI). Most common cause of acute adrenal insufficiency is sepsis and the SIRS.23,24 Abhay Gundgurthi et al $^{23}$ reported a mean basal cortisol $95.97 \pm$ $83.32 \mathrm{nmol} / \mathrm{L}$, post ACTH cortisol $270.32 \pm 140.25 \mathrm{nmol} / \mathrm{L}$ and Delta cortisol $174.62 \pm 113.57 \mathrm{nmol} / \mathrm{L}$, in 37 adrenal insufficiency patients out of 89 studied patients. The present study shows mean basal cortisol of $137.51 \pm 68.18 \mathrm{nmol} / \mathrm{L}$, post ACTH cortisol $605.92 \pm 389.67 \mathrm{nmol} / \mathrm{L}$ and Delta cortisol $135.51 \pm 68.25 \mathrm{nmol} / \mathrm{L}$ in 25 adrenal insufficiency patients out of 46 studied patients. [Table-7]. Basal cortisol level solely cannot be relied on to detect all cases of AI. ${ }^{23}$ From studied group, 17 patients had basal cortisol $\leq 500 \mathrm{nmol} / \mathrm{L}$. and 25 patients had increment of S. cortisol $\leq 250 \mathrm{nmol} / \mathrm{L}$. Out of 17 patients whose basal cortisol was $<500 \mathrm{nmol} / \mathrm{L}, 5$ patients had $>250 \mathrm{nmol} / \mathrm{L}$ of S. cortisol after ACTH stimulation test.

14 patients from 25 patients had increment of S. cortisol $\leq 250 \mathrm{nmol} / \mathrm{L}$, but they did not have basal cortisol $\leq 500$ $\mathrm{nmol} / \mathrm{L}$. Only 9 patients had both basal cortisol $\leq 500 \mathrm{nmol} / \mathrm{L}$ and increment value of $\mathrm{S}$. cortisol after ACTH $\leq 250 \mathrm{nmol} / \mathrm{L}$. Two patients from control group had subnormal basal cortisol but showed increment $>250 \mathrm{nmol} / \mathrm{L} \mathrm{S}$. cortisol after ACTH stimulation test. Hence, at best, basal cortisol can be used to screen for suspected AI and those with a low basal cortisol will need a stimulation test to confirm or exclude AI. 


\section{CONCLUSION}

Adrenal insufficiency is often present in critically ill patients, ${ }^{25}$ but difficult to prove due to non-availability of Synacthen stimulation test. In this study, we have shown that AI can be easily and efficiently diagnosed using Acton Prolongatum, which is an easily available long acting version of ACTH.

HPA dysfunction is common in severely ill patients. Even slight impairment of the adrenal response to severe illness can increase morbidity and mortality, and we believe that low serum cortisol levels may be the cause rather than the consequence of poor outcome in these patients. Therefore, a high index of suspicion for adrenal insufficiency is required in all critically ill patients, particularly those with refractory hypotension. All patients with suspected HPA dysfunction should be treated with stress doses of corticosteroids. The result of our study points to the possibility of existence of subnormal adrenocortical response in some critically ill patients, who do not respond adequately to the standard optimal therapy. Therapeutic implication arising out of the study is the possible role of glucocorticoids as an adjunctive therapy, in the hope of a more favourable outcome.

\section{REFERENCES}

[1] Jurney TH, Cockrell JL, Lindberg JS, et al. Spectrum of serum cortisol response to ACTH in ICU patients. Correlation with degree of illness and mortality. Chest 1987;92(2):292-5.

[2] Reincke M, Allolio B, Wurth G, et al. The hypothalamicpituitary-adrenal axis in critical illness: response to dexamethasone and corticotropin-releasing hormone. J Clin Endocrinol Metab 1993;77(1):151-6.

[3] Hinshaw LB, Beller BK, Chang AC, et al. Corticosteroid/antibiotic treatment of adrenalectomized dogs challenged with lethal E. coli. Circ Shock 1985;16(3):265-77.

[4] Darlington DN, Chew G, Ha T, et al. Corticosterone, but not glucose, treatment enables fasted adrenalectomized rats to survive moderate hemorrhage. Endocrinology 1990;127(2):766-72.

[5] Ledingham IM, Watt I. Influence of sedation on mortality in critically ill multiple trauma patients. Lancet 1983;1(8336):1270.

[6] Reichlin S. Neuroendocrine-immune interactions. N Engl J Med 1993;329:1246-53.

[7] Chrousos GP. The hypothalamic-pituitary- adrenal axis and immune mediated inflammation. N Engl J Med 1995;332(20):1351-62.

[8] Annane D, Bellissant E, Bollaert PE, et al. The hypothalamic-pituitary-adrenal axis in shock. $\mathrm{Br} \mathrm{J}$ Intensive Care 1996;6:260-8.
[9] Lamberts SW, Bruining HA, De Jong FH. Corticosteroid therapy in severe illness. $\mathrm{N}$ Eng J Med 1997;337(18):1285-92.

[10] Pugeat M, Bonneton A, Perrot D, et al. Decreased immunoreactivity and binding activity of corticosteroid-binding globulin in serum in septic shock. Clin Chem 1989;35(8):1675-9.

[11] Firschein HE, Devenuto F, Fitch WM, et al. Distribution of injected cortisol- 4- $\mathrm{C}^{14}$ in normal and shocked rats. Endocrinology 1957;60(3):347-58.

[12] Melby JC, Spink WW. Comparative studies on adrenal cortical function and cortisol metabolism in healthy adults and in patients with shock due to infection. J Clin Invest 1958;37(12):1791-8.

[13] Schein RM, Sprung CL, Marcial E, et al. Plasma cortisol levels in patients with septic shock. Crit Care Med 1990;18(3):259-63.

[14] Matot I, Sprung CL. Corticosteroids in septic shock: resurrection of the last rites? Crit Care Med 1998;26(4):627-30.

[15] Sibbald WJ, Short A, Cohen MP, et al. Variations in adrenocortical responsiveness during severe bacterial infections. Unrecognized adrenocortical insufficiency in severe bacterial infections. Ann Surg 1977;186(1):29-33.

[16] Finlay WE, McKee JL. Serum cortisol levels in severely stressed patients. Lancet 1982;1(8286):1414-5.

[17] McKee JL, Finlay WE. Cortisol replacement in severely stressed patients. Lancet 1983;1(8322):484.

[18] Grieg WR, Maxwell JD, Boyle JA, et al. Criteria for distinguishing normal from subnormal adrenocortical function using the Synacthen test. Postgrad Med J 1969;45(523):307-13.

[19] Dorin RI, Qualls CR, Crapo LM. Diagnosis of adrenal insufficiency. Ann Intern Med 2003;139(3):194-204.

[20] Friedman M. Comparison of duration of activity of corticotrophin-gelatin and corticotrophincarboxymethyl cellulose. Brit Med J 1967;3:409-10.

[21] Annane D, Sebille V, Troche G, et al. A 3-level prognostic classification in septic shock based on cortisol levels and cortisol response to corticotropin. JAMA 2000;283(8):1038-45.

[22] Gundgurthi A, Garg MK, Dutta MK, et al. Intramuscular ACTH stimulation test for assessment of adrenal function. Journal of the Association of Physicians of India 2013;61(5):320-4.

[23] Marik PE, Zaloga GP. Adrenal insufficiency during septic shock. Crit Care Med 2003;1:141-5.

[24] Zaloga GP, Marik P. Hypothalamic-pituitary-adrenal insufficiency. Crit Care Clin 2001;17(1):25-41.

[25] Frost P, Wise MP. Recognition and early management of the critically ill ward patient. British journal of hospital medicine 2007;68(10). 